\title{
FRONTERAS INTERNAS Y HEGEMONÍAS PREDICATIVAS EN CHILE: EL CASO DE LA PATAGONIA AUSTRAL
}

\author{
INTERNAL BORDERS AND PREDICATIVE HEGEMONIES IN CHILE: THE CASE \\ OF PATAGONIA AUSTRAL
}

\author{
Juan Carlos Rodríguez Torrent ${ }^{1}$, Nicolás Gissi Barbieri y Fernando Mandujano Bustamante ${ }^{3}$
}

\begin{abstract}
Chile se ha destacado históricamente no solo por sus fronteras externas sino también por sus confines internos. En este artículo se presentan resultados de proyectos de investigación Fondecyt que reflexionan sobre las fronteras internas y sobre la frontera chileno/patagónica que ha sido emblemática, donde todavía al sur de Puerto Montt se dice "voy a Chile" cuando se desea ir al centro o norte, marcando una distancia social y geográfica. Sostenemos que lo que ha predominado como fundamento de la territorialización nacional ha sido una metanarrativa sobre la soberanía del país, es decir, sobre el límite material y simbólico, siendo siempre el sur austral una referencia lejana de territorios periféricos y de baja integración. Ha predominado una hegemonía predicativa o geo-referencia marcada por el paisaje y la conectividad, que se pone en juego para construir la identidad como una imagen legítima, representando empíricamente un conjunto de fracturas y modos de ser asociados a experiencias históricas y localizadas muy diferentes al imaginario nacional homogéneo. La continuidad de esta frontera dificulta el desarrollo armónico de la zona austral de Chile, así como de un proyecto colectivo que requiere equidad territorial y solidaridad inter-regional.
\end{abstract}

Palabras claves: frontera, hegemonía predicativa, aislamiento, Patagonia.

Chile has historically stood out not only for its external borders but also for its internal borders. In this article, we present results of Fondecyt research projects that reflect on internal borders and on the Chilean / Patagonian border that has been emblematic, where still south of Puerto Montt the phrase "go to Chile" is said when people want to go to the center or north, marking a social and geographical distance. We hold that what has prevailed as the basis of national territorialization has been a meta-narrative on the country's sovereignty, that is, on the material and symbolic limit, always being the austral south a distant reference of peripheral territories and low integration. A predicative hegemony or geo-reference marked by landscape and connectivity has been predominant, which is at play in the construction of identity as a legitimate image, representing empirically a set of fractures and modes of being associated with historical and localized experiences that are very different from homogeneous national imaginary. The continuity of this border hinders the harmonious development of the southern zone of Chile, as well as a collective project that requires territorial equity and interregional solidarity.

Key words: Border, predicative hegemony, isolation, Patagonia.

Revisando las lógicas fundacionales de los Estados-nación en Latinoamérica en el siglo XIX, es evidente que algunos de los países fueron imaginados antes de ser explorados, dibujados por los funcionarios en oficinas capitalinas antes de ser conocidos, incluso estigmatizados o sacralizados por voces canónicas algunos de sus territorios. En el caso de Chile, Charles Darwin, Diego Barros Arana y Benjamín Vicuña
Mackenna sancionaron las características de grandes extensiones territoriales australes. El naturalista definió a las tierras australes de la Patagonia como "un desierto" por su condición de despoblada; el historiador definió su territorio como "un inmenso erial, de vegetación raquítica y espinosa"; y, el urbanista, como "un pedazo de océano petrificado, estéril e insensible solitario, callado y maldito, que

\footnotetext{
${ }^{1}$ Centro de Investigaciones en Vulnerabilidades e Informalidades Territoriales (CINVIT), Facultad de Arquitectura Universidad de Valparaíso, Avenida el Parque 570-Valparaíso, Chile. juancarlosrodriguezt@ yahoo.com

${ }^{2}$ Departamento de Antropología, Universidad de Chile, Av. Ignacio Carrera Pinto 1045, Nuñoa, Santiago, Chile. ngissi@uchile

${ }^{3}$ Facultad de Educación, Universidad de Playa Ancha, Av. Playa Ancha 850-Valparaíso, Chile. fm@upla.cl
}

Recibido: octubre 2017. Aceptado: junio 2018.

http://dx.doi.org/10.4067/S0717-73562018005001501. Publicado en línea: 6-agosto-2018. 
constituía una verdadera imagen del infierno" (Osses 2008:51).

Hasta avanzado el siglo XX, la Patagonia fue una zona demasiado lejana, dibujada solo en papel, con dificultades para identificar rasgos diacríticos en sus habitantes y carente -en la épocade riquezas minerales importantes que movilizaran interés. La vertiente occidental llevó ese desamparo y aislamiento al extremo; más de $1.000 \mathrm{~km}$ al norte del Estrecho de Magallanes, se mantuvo inaccesible por los campos de hielo, también como un territorio enfrentado a la costa del Pacífico en miles de islas y fiordos en el peor clima de América austral. Desde el norte, durante casi todo el siglo XX, la zona de Aysén estuvo desconectada por tierra del resto de Chile. Tan remota e inaccesible es la figura geográfica, que tan solo hace casi 15 años Simon Worrall, en el National Geographic Magazine (2004), dice que ha sido una tierra tan extraña como Timbuktu o Shangrila, un lugar de mitos y leyendas, y para otros una compañía textil (la marca Patagonia) más que un lugar.

Mucho de estas rúbricas territoriales tienen que ver con el lugar de enunciación como señalara E. Said (2002); con las condiciones específicas para producir significado y estructuración de la recepción, lo que expresa un conjunto de fuerzas institucionalizadas que decantan en un modo de pensamiento ${ }^{1}$. Condición asociada a la premura burocrática y política de "fijar fronteras" y construir el mapa para marcar el "territorio nacional" como "acto de vigilancia" y "principio de autoridad" (Harley 2005:82), aunque prescindiendo de conocimiento etnológico y del paisaje; sin considerar las formas de apropiación ambiental, de ocupación y movilidad de las poblaciones originarias avecindadas, lo que implicó que una soberanía como capacidad soberana para satisfacer de manera autónoma sus proyectos y necesidades, se impusiera sobre otras múltiples soberanías. El resultado territorial y simbólico de la operación para establecer en un mapa la línea/límite política administrativa, se tradujo en bajos niveles de control estatal, pobre asimilación a la idea de nación y propensión al cambio de identidad nacional, producto de que las relaciones fueron simultáneamente de conflicto y cooperación. Y, en paralelo, como acertadamente señalan Núñez et al. (2016), el vacío geográfico (conocimiento) se convierte en vacío étnico (reconocimiento), en "silencio geográfico" y silencio étnico de algunas soberanías, de modo que la huella histórica de este límite "que define la territorialidad estatal" (Benedetti y Laguado 2013:453), la frontera como "dispositivo zonal" y como "sucesión de localizaciones" (Benedetti y Laguado 2013:453), comenzaría recién con las asignaciones de tierras a estancieros a comienzos del siglo XX. Condición que reduce la memoria de la representación geográfica, social y cultural a la ocupación al ciclo ganadero lanar, los cueros y carneo con destino a Puerto Montt, Tomé y Santiago.

Esto significó que, como esfuerzo colonial e ideológico lo susceptible de ser representado espacialmente a través del régimen discursivo sobre el territorio es lo estático y no lo errante, como contorno hegemónico de un modo de pensamiento citadino que excluyó el reconocimiento de la adaptación de otros grupos (i.e. mapuches y tehuelches); la preexistencia nómade costera e interior no se considera (i.e. chilotes continentales), no se reconoce y se encuentra, o es subsumida al código binario barbarie-civilización.

Se constituyeron así categorías históricas y geográficas que se convirtieron en referencias obligadas y recurrentes difíciles de sostener con la evidencia empírica, como es la altitud de la cordillera o que ésta constituye una barrera natural, sin observar que en la Patagonia los pasos entre el oriente y el occidente son bastante expeditos al seguir las hoyas hidrográficas y los valles transversales, dando forma a un intercambio permanente al margen de la línea de vigilancia, que articuló los espacios periféricos frente a los Estados nacionales (Torres 2002) ${ }^{2}$. Se ha convivido en el siglo XIX y XX con la obsesión de creación de Estados unitarios y uniformes a través de las líneas demarcatorias administrativas, que establecieron una memoria moderna anclada en batallas épicas y grandes héroes que configuran una memoria cívica portable y susceptible de ser distribuida dentro del mapa imaginario de Chile (y también en Argentina). Todo ello, sustentado en un déficit mayor de conocimiento y exploración geográfica y etnológica por parte del Estado (Figura 1), que claramente hubo de inducir "transformaciones culturales" para chilenizar y argentinizar a las poblaciones que estaban al margen de contenidos ideológicos del ser nacional, para ayudar a distinguir y distinguirse; sin por ello terminar con un habitus fronterizo preexistente (Baeza 2009:35), porque las poblaciones fronterizas usan también los límites para su propio beneficio, convirtiéndolo en una especialidad de su saber (i.e. comerciar, traficar). Sin embargo, solo se trataba de "encuadrar las actitudes y las costumbres cívicas a los requisitos de una legalidad desconocida hasta entonces" (Maggiori 2012:9), es decir, una exportación enunciativa de valor ante una línea fija, y fronteras que se movían elásticamente y que operaban como membrana y estaban a distancia de la autoridad del Estado.

El historiador Mateo Martinic refuerza esta tesis de la falta de conocimiento, que se traduciría en el tiempo en condiciones de periferia y bajo agenciamiento estatal: "La ignorancia tradicional de la dirigencia chilena en lo tocante al conocimiento de la geografía nacional -léase austral-, sumada al 


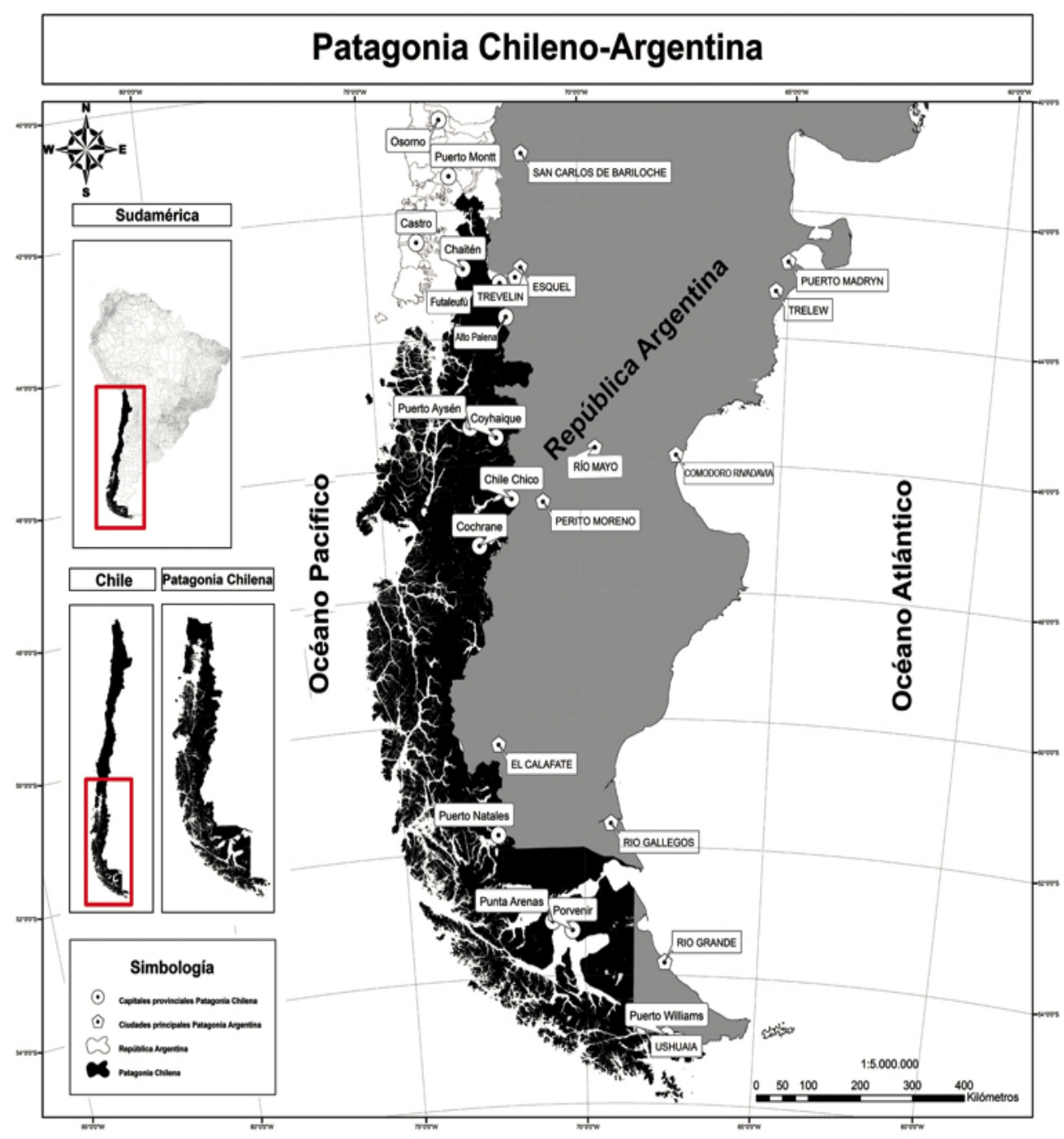

Figura 1. Territorio de la Patagonia Chilena-Argentina. Fuente: elaboración de los autores con base en el Mapa general de la Patagonia del Instituto Geográfico Militar (IGM-Chile). Escala 1: 5.000.000.

Patagonia Chilena-Argentina. Source: Authors' own elaboration based on the general Map of Patagonia of the Geographic Military Institute (IGM-Chile). Scale 1: 5,000,000. 
desinterés político (no había votos) y económico (no había recursos naturales explotables a la vista)" (Martinic 2011:37), son finalmente los causantes del bajo nivel de desarrollo y apropiación territorial del siglo XX y XXI. Núñez et al. (2017), ve con ello la creación de una geografía de la marginalidad y la exclusión, ya que no pueden ser estos territorios incorporados al imaginario de la modernidad, el desarrollo y el proyecto de la nación de las zonas centrales como lo demuestra la Geografía Económica de CORFO $(1950,1960)$. La ignorancia sobre nada menos que un tercio del territorio y de la evidente figura binacional de la frontera que se imponía sobre el límite, unida a la importancia económica y geográfica de la zona del Estrecho de Magallanes como ruta interoceánica, hizo que solo un punto fuera convertido en el lugar más significativo para la definición territorial de la Patagonia, quizá la única y auténtica bandera de soberanía ${ }^{3}$.

Si el territorio de Magallanes fue identificado por unir los dos océanos más que por otro valor, en Aysén la presencia fue menos visible para el Estado; la única acción temprana del Estado consistió en "conceder inmensos espacios de tierra a personas o sociedades que se comprometían a poblarla y hacerla producir" (Carreño 2003:123). Constituyó desde los últimos años del siglo XIX y las dos primeras décadas del XX, no solo una tierra de "entre medio" (Bandieri 2011:220; Torres 2002:329) para diferenciarla de las acciones económicas y de las dinámicas poblacionales y culturales de los polos comerciales de MagallanesRío Gallegos-Ushuaia y Bio Bio-Puerto Montt-Río Negro-Neuquén, sino que sus hombres y mujeres fueron también de "entre medio". Los nacidos ahí no tenían actas de nacimiento, disponían de poca o nula información de lo nacional, no sabían a qué país recurrir frente al bandolerismo y el correo lo retiraban en Argentina (Ivanoff sf). Crespo y Tozzini (2013), señalan que en Argentina las familias mapuches fueron clasificadas oficialmente como chilenas o campesinas, como modo simplificado de discurso de adscripción étnica en un territorio poroso e integrado; mientras, en el Chile receptor se forja la anatomía de la asimilación sin integración ni reconocimiento, como contenido retórico que "evalúa, mide y convence", frente a los que "nombran, ubican y cuentan" (Harley 2005:81).

El poblamiento, desde la perspectiva de la actividad económica capitalista ganadera, que data de comienzos del siglo XX con las grandes concesiones de tierras (Sociedad Industrial del Aisén, Sociedad Ganadera Río Cisnes y Sociedad Explotadora del Baker) ${ }^{4}$, según Ibar (1973:8) registraba tempranamente solo 200 habitantes; el censo de 1920, reconocía 1.660; y el de 1932, 9.714; Ivanoff (sf:105) sostiene que en el Lago Buenos Aires (General Carrera), solo había en 1.930, 1211 personas (765 varones y 446 mujeres). Algunos eran chilenos repatriados desde Argentina como resultado del Laudo Arbitral de 1902, los que fueron expulsados en el gobierno de Roca (1898-1904) -que tenía experiencia ganada en limpieza étnica en la "campaña del Desierto"- con sus ganados y que se establecieron dispersamente en Futaleufú, Palena, Lago Verde, Valle Simpson, Lago Buenos Aires, Baker y Río Mayer (Ivanoff sf).

En lo que puede resultar hoy un dato casi anecdótico, en 1903 se concedió por decreto de Estado a don Luis Aguirre, de Punta Arenas, la ocupación por 20 años de los Valles de Coyhaique, Ñiriguao y Mañihuales. Comprometiéndose, por una parte, a instalar una colonia de 100 familias de origen sajón, es decir, una migración "con fuerza retórica" y que "impresionaba a burócratas santiaguinos" (Martinic 2014:220-221), valorada como "deseable" y que contaba con la experiencia de la colonización alemana en la Araucanía; y, por otra, a realizar inversiones que pudiesen ser constatadas al final de la concesión (infraestructuras y poblados). Mientras, del otro lado de la baja cordillera, hubo tempranas decisiones: en 1865 se establecieron las primeras colonias galesas en el valle del Río Chubut, las que fueron asistidas por el gobierno de Buenos Aires, discutiendo opciones de infraestructuras y servicios para que pudiesen distribuir la producción triguera y ganadera. Ello, da origen a los poblados de Esquel, Trevelin, Río Mayo y la Colonia 16 de Octubre (Torres 2002:331).

No hubo colonización sajona ni gran infraestructura y sí latifundio o "neofeudalismo" (Osorio 2014:22). Frente a la "venta de ilusiones" sobre las características del poblamiento, ya que el territorio - preso del discurso modernizador- se imaginaba en Santiago (Martinic 2014:220), "la única mejora o adelanto consistía en introducir ganado, para lo cual era necesario incendiar los bosques" (Otero 2006:83). En una tierra que parecía infinita, se establecieron tensiones con una apropiación de terrenos de carácter espontáneo de familias provenientes desde Argentina frente a las de los asignatarios (Ibar 1973:10; Ivanoff sf). Como bien indica Baeza (2009:34), en un largo periplo "muchos de estos colonos habían sido corridos de la zona central de Chile. Instalados luego en Argentina, fueron expulsados por las autoridades, por lo que, por último, buscaron reinstalarse del lado chileno de la frontera".

Esta forma de ocupación fue sin fundaciones y habilitaciones conducentes a fortalecer la presencia del Estado (Futaleufú, Alto Palena, Lago Verde y Aysén), y tuvo por resultado una frontera inconclusa del lado oriental. Inestable y porosa por la movilidad ligada a oportunidades económicas, de trabajo y redes de parentesco (Saénz 2016); llena de formas 
de significación difusas, con acusaciones de mayores rasgos de argentinización o chilenidad, conimportación de héroes de lugares centrales, con bautismo de lugares con nombres propios de personajes, actos conmemorativos, con fechas de la liturgia estatal y con el refuerzo de destacamentos militares, por lo que su objetivo no sólo buscaba "afirmar la existencia de una unidad política, sino también trabajar para producirla" (Baeza 2009:37). El proceso de producción de esta argentinidad y chilenidad sui generis, sin romper con las prácticas de circulación históricas ${ }^{5}$, por un lado, en la cara oriental produjo el agenciamiento de galeses, chilenos, mapuches (Trevelin), y más al sur los tehuelches (Río Mayo); por otra, en la cara occidental, la cohabitación de chilenos-argentinos, chilotes y chilenos del norte (Futaleufú y Alto Palena). Todos ellos fueron enfrentados a la más auténtica argentinidad y chilenidad, aun cuando muchos no supieran qué bandera izar; y, que nunca lograran hacer coincidir la línea con las características de la frontera. El territorio de colonización de Aysén (actual Provincia de Palena y Región de Aysén), solo adquiere existencia plena en 1927, con el Presidente Carlos Ibáñez del Campo, siendo la última zona en alcanzar reconocimiento y ser incorporada a la nación.

Estas procedencias geográficas, raciales y culturales, configuradas como epistemología geocultural, dejaron como herencia de cultura vivida y la falta de control y agenciamiento estatal, una idea de "región binacional", es decir, "el resultado de complejos territoriales, donde los subsistemas de producción y circulación aparecen reflejados a través de los flujos y redes de relaciones sociales y de mercados" (Bandieri 2011:220; Torres 2002:325). Y, si bien en los últimos 30 o 40 años del siglo $\mathrm{XX}$ produjo algo del efecto de argentinizar y chilenizar -ya con la presencia de destacamentos militares permanentes-, dejó en la investigación cuatro problemas etnográficos y etnológicos por resolver en el ámbito del mito de lo nacional, la identidad y la estratificación: (1) el problema de la autenticidad para los habitantes de la zona, es decir, reconocimiento sobre quiénes son los primeros, en función de qué y sus derechos (Figura 2); (2) el problema de los outsiders, es decir, los que llegaron en otro momento y que también se sienten pioneros, locales y defensores de la cultura patagónica; (3) la invisibilización absoluta de población mapuche, tehuelche y chilota (continental); y, (4) los habitantes más antiguos de Futaleufú, Alto Palena y Coyhaique son emigrantes en algún sentido, pero abreviadamente esta ideología nacionalista no adscribe tan claramente al ser chileno como totalidad, sino a un particular modo de serlo en su cotidianeidad. Es decir, hay un gaucho que convive con un huaso "exportado" del Chile central, un chamamé con una cueca, una jineteada que tiene al frente una medialuna para el rodeo, lo que significa -al menos- aspectos híbridos.

Entonces, relevamos la idea de frontera como cuestión basal, diferenciandola de la línea/límite política, ya que se trata de una operación fundacional de los estudios culturales desde fines del siglo XX. Más allá de su carácter geográfico o geopolítico, la fronterización arbitraria corresponde en este caso a un dispositivo pedagógico; el que se encuentra asociado a una forma de enunciación y administración de un conjunto de conocimientos y prácticas de readaptación para la definición de una ciudadanía específica, propio del interés del Estado para generar condiciones de igualdad formal. De este modo, la frontera es por definición demarcatoria de regulaciones de ingreso-egreso de personas y bienes; expresa límites y diferencias, y actúa instruccionalmente como recurso frente a la desviación. De ahí que, en la Patagonia, conforme a las tempranas y naturalizadas enunciaciones, existan problemas de apreciación zonal, demandas y necesidades específicas que buscamos discutir.

\section{Fronteras y Territorios: Conceptualizando los Espacios}

Hay un concepto que suele acompañar estas reflexiones introducidas: los límites, o mejor aún, de las fronteras. En un sentido moderno, evocador de la construcción de los Estados-nación de los siglos XIX y XX, la frontera corresponde al complejo infraestructural y taxonómico, y determina lo propio y lo ajeno. Se juegan temas de Estado: influencia, regulación, control y poder; de orden cultural y económicos, así como la imagen de la nación. Por ello, en los marcos de la globalización, los antropólogos han relevado su importancia frente a re-territorializaciones, como "reto académico" y la necesidad de plantearse la nación en sus "formas de figuración" (Vich 2008:11), porque se compromete una visión espacial y también temporal. Su sola presencia alude a diferentes memorias sociales.

Las fronteras y sus límites no son solo materiales (alambres, muros), a veces son naturales (mares, ríos, cordilleras, bosques, desiertos), y/o simbólicas (imágenes, ideales, utopías). La frontera más que un límite o línea precisa implica un territorio en el que hay infraestructuras y sistemas de acciones, y por tanto identidades y alteridades sociales en movimiento, así como cruces, rutas, desbordes, amenazas y transgresiones. Una frontera opera como categoría organizativa de la vida social (Rodríguez et al. 2018); "es una región o zona en la que entran en contacto dos o más culturas, sociedades, grupos étnicos o modos de producción distintos" (Hall 2007:247). Es 


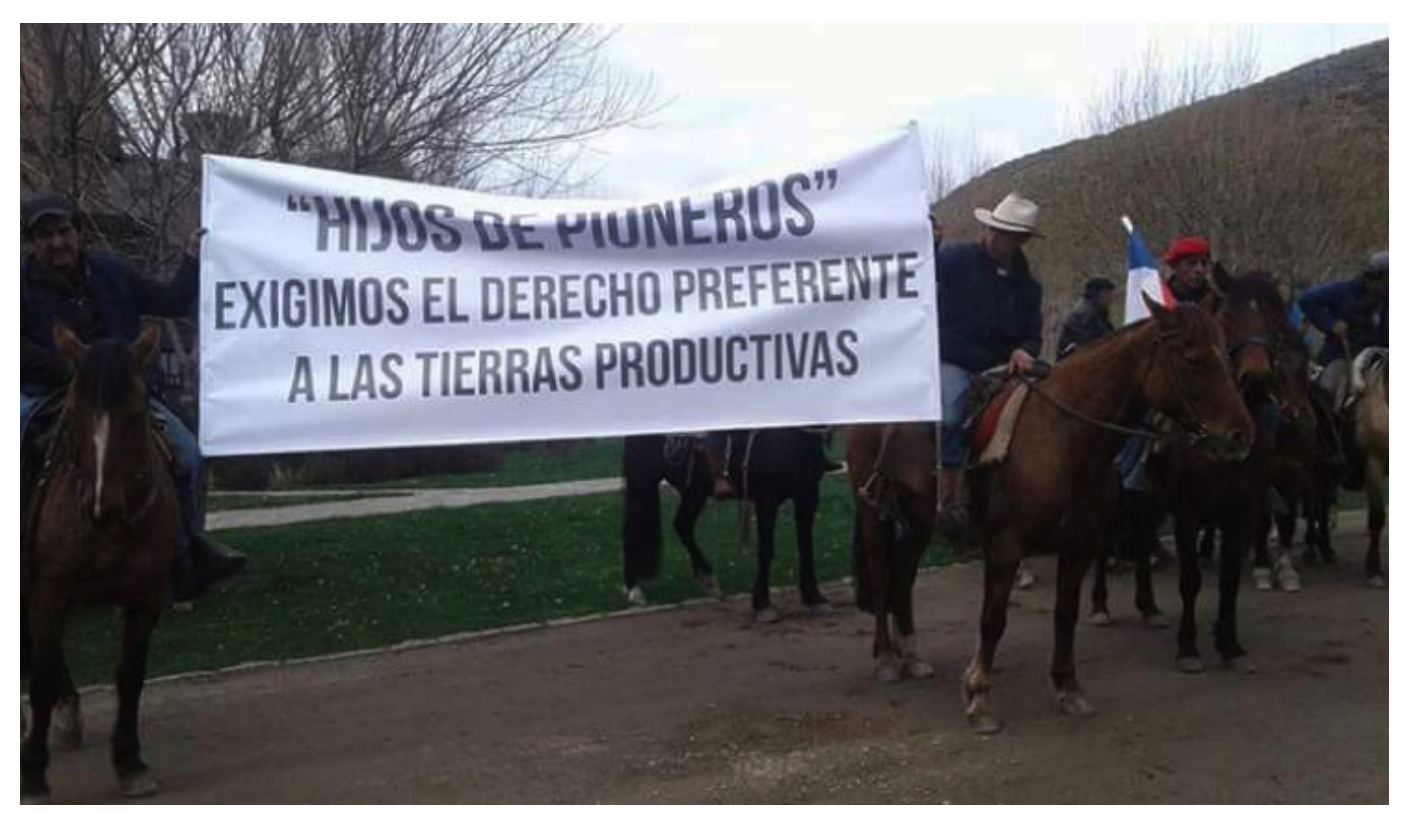

Figura 2. Fotografía en la que se ve representada la distinción y la autenticidad. Tomada en septiembre de 2017, por Juan Sáenz Passeron.

Photograph representing distinction and authenticity. Photograph taken by Juan Sáenz Passeron in September 2017.

una espacialidad y temporalidad in-between, "entre medio" (Bhabha 1996) de dos o más actores, que unen al interior y separan del exterior. Implica tanto la inclusión como la exclusión de lugares que se cruzan con la multi-temporalidad territorial, creando cronotopos (interior/pasado nuestro ya incorporado y un exterior/futuro por suceder).

Políticamente, contiene la pretensión de la "comunidad imaginada" (Anderson 2006) para que no se desborde; o, en términos de Chatterjee (2008), llenar de contenido plural un significante vacío, donde existen poblaciones y menos ciudadanos, más demandas particulares que derechos de corte universal. La frontera dentro de los límites de la nación abre en su conjunto la posibilidad epistémica para también considerarla como intersticio y metáfora fundante relacional, superándose el análisis reduccionista de los procesos socioculturales localizados como unidades autónomas y abstractas. Asimismo, las fronteras revelan similitudes y diferencias, dominaciones y rebeldías, en rigor "configuraciones" (Elías 1979:25), porque también son lugares polifacéticos, multiculturales, multisignificantes y con formas culturales up down, que crean lenguajes propios, unidades socio-espaciales sui generis, dado por relaciones y escenarios en permanente construcción. Confluyen identidades arraigadas y otras emergentes, experimentándose contrastes y desigualdades; también se pueden des-territorializar o se refundan según las fuerzas políticas y económicas que estén operando. Se redescubren en virtud de nuevos intereses y se recolonizan por la llegada de nuevos actores y agenciamientos; o se abandonan, y las identidades marcadas e inscriptas en el territorio se hibridizan producto de los flujos, se reformulan en función de procesos aculturativos o transculturativos.

No siempre las fronteras de los Estados-Nación son externas. Muchas veces algunos espacios geográficos y étnicos son separados y/o postergados del resto de la población nacional por estigmatizaciones, desconocimiento o presencia-ausencia de recursos, políticas focalizadas o por la misma presencia y subjetividad de funcionarios del Estado, asumiendo condiciones particulares desde la perspectiva de la integración interterritorial. En el caso chileno, como señala el historiador Jocelyn-Holt (2004:18):

La atención que merece la zona australpatagónica me parece, pues, fundamental, tanto más incluso, porque es ahí donde se seguirá centrando nuestro destino geográfico último o manifiesto, desde aquel entonces hasta nuestros días. Ello sin olvidar el hecho de que estos territorios quedaron, desde muy temprano, al margen de todo acceso y dominio posible... la ironía máxima entre nosotros es que será esta zona, aun cuando fuera de nuestro alcance, la que persistirá como objetivo ulterior de nuestras obsesiones. 
Estos territorios quedan aislados debido a la jerarquización de regiones o marcados como puntos específicos como ocurrió con Punta Arenas y el tráfico portuario interoceánico, considerándose la riqueza de recursos económicos, las posibilidades para incorporar infraestructuras, la recuperación y rentabilidad de las inversiones, zonas políticamente estratégicas y las densidades demográficas ${ }^{6}$.

\section{Consideraciones Metodológicas}

Presentamos aquí algunos resultados del trabajo de campo realizado entre los años 2012-2016, en la Región de Los Lagos (provincia de Palena) y la Región de Aysén, zonas en las que se están desarrollando nuevas formas de territorialización, debido a la modificación de los vínculos entre lo local y lo global ocurridos durante las últimas dos décadas, lo que ha permitido plantear varias cuestiones teóricas. Para lograr este análisis de tipo cualitativo, hicimos registros etnográficos basados en un conjunto de observaciones y entrevistas semiestructuradas realizadas fundamentalmente a pequeños productores, quienes realizan actividades ganaderas (vacunos y ovejas), madereras (leña), turismo rural, pescadores artesanales, transportistas y pequeños comerciantes. También a funcionarios del aparato público regional de distintos servicios y municipales, ubicados en zonas urbanas y rurales. El objetivo de las entrevistas y descripciones es dar cuenta de una antigua pero renovada ruralidad y demandas urbanas constituidas a partir de la presencia de nuevos actores y fuerzas nacionales y globales (mineras, energéticas, acuícolas, turísticas y simbólicas) que están operando en el espacio y reconfiguran las posibilidades de reproducción local hasta ahora conocidas. Esta producción de datos primarios se complementó con información secundaria disponible en distintas bases de datos de instituciones del Estado y tesis de grado, para discutirlas conforme a una hipótesis de trabajo, alojada en un programa de investigación sobre los procesos de construcción histórica y simbólica del territorio patagónico.

Desde el trabajo etnográfico, se privilegió una estrategia de registro multilocalizada, de modo de facilitar la imagen de co-construcción territorial, avalada por la evidencia de participación de actores des-localizados y que afectan los contenidos del territorio. De este modo, triangulamos información para indagar desplazamientos, representaciones de sujetos, observando los arraigos y desarraigos, estableciendo tendencias en la movilidad y conociendo las aspiraciones que van dando forma a esta frontera interior.

\section{Territorio y Hegemonía Predicativa en la Patagonia}

Lo que ha predominado como fundamento de la territorialización en la Patagonia chilena ha sido una metanarrativa sobre la soberanía del país, es decir, sobre el límite (o línea), siendo siempre el sur austral una referencia lejana, de saber con poco contenido teórico y conocimiento efectivo para la población del centro. Existe una hegemonía predicativa o geo-referencia simbólica que se pone en juego para construir la identidad como una imagen legítima y una definición ontológica, que corresponde como sostiene Laclau (2002:122): a "una relación por la que un contenido particular asume, en un cierto contexto, la función de encarnar una plenitud ausente". Sabemos, genealógicamente no hay posibilidad de una representación de la totalidad dentro de los límites, porque la identidad es siempre relacional; inclusive, porque en el "nosotros" que posibilita una comunicación intragrupal, siempre aparece una diferencia que permite construir el "ellos".

Se desarrollaron dos actos performativos de hegemonía predicativa y de imaginería simbólica chilena, para dar cuenta de "la larga y angosta faja de tierra", ubicada al sur del mundo. Por una parte, la producción épica-simbólica para resaltar y mantener vigente una memoria colectiva centrada en el acontecimiento histórico que deviene en celebración cívica; por otra, la generación de espacios públicos y museos que avalan y testimonian la fe en un proceso colectivo, que petrifican los contenidos trascendentes de un ser nacional. Cuestiones que, como sostiene Anderson (2006), permitió que la retórica nacionalista se difuminara a partir de la instrucción pública, apoyado del impreso, el censo y el mapa, que facilitaron la condición posible de un nosotros que llegó al límite austral. Otros países fueron más allá; como en el caso de México, donde se conectaron simbólicamente con culturas anteriores a las coyunturas independentistas a través del desarrollo temprano de la etnología y potentes guiones museográficos como formas de representación (Bonfil 1990). Ahí se encuentran los fundamentos de los nacionalismos culturales, las identidades y los cultos iconográficos que atraviesan a Latinoamérica.

En el establecimiento de la nación genealógica que articula y re-significa herencias y préstamos culturales para que un sujeto pueda nombrarse a sí mismo y desde lugares diversos, se prescinde del lugar ocupado en la estructura social y de su ubicación territorial. En esta omisión obsecuente, surgen tres cuestiones importantes que tendrán efecto en la constitución de fronteras externas e internas de Chile, 
la Patagonia Austral y en la titularidad colectiva: (1) la unidad territorial como bien superior a las diferencias preexistentes, (2) el imaginario del desarrollo como figura del progreso, fe en el futuro, justicia y equidad, y (3) el ideal soberano como principio de autonomía y diferenciación.

Se debe comunicar y hacer entrar en el universal simbólico la atribución de titularidad, imponiéndose etnocráticamente frente a otras posibles alternativas de legitimidad étnica o religiosa, ya que comportan un sofisma taxonómico (Máiz 2008) que subsume las diferencias interiores propuestas por el límite fronterizo. Es decir, la figura de un nacionalismo cívico se iguala con el carácter de una etnicidad homogénea, y ésta con el mapa que marca la línea, porque la cultura y la sociedad se constituye como una dimensión abstracta, arrebatada de su base territorial como soporte de la experiencia y su sistema de acciones; y, simultáneamente se da lugar al margen, ya que la identidad como esencialismo teleológico que fija el destino del sujeto, no puede imponerse a la totalidad de lo existente. Entonces, como los poblados y ciudades no están en la línea exactamente, es en estas unidades interiores y de frontera donde se expresa la vincularidad normativa del contrato social y su contradicción: la igualdad formal para todos (autonomía y libertad) y desigualdad material, social y económica (realidad particular de los sujetos).

A partir de la operación historiográfica que da forma a esta condición mono-cultural, que hace equivalente lo político y lo cultural como límite, que pone en evidencia el poder del Estado, su proyecto modernizador y su condición de clase, se elimina el grado de diversidad -social, cultural y espacialexistente en el colectivo y sus formas de interacción política, científica, económica, comunicacional, ideológica, social, ambiental y movilidad territorial. Se invisibiliza, que nacer, habitar y experimentar en unas estructuras históricas particulares de la Patagonia Austral (i.e.), determina una condición permanente de subalternidad, marginalidad y exclusión, injustas en símismas; impidiendo que se haga efectivo el discurso ético de la igualdad y la simetría no solo desde la orientación económica, sino como relación armónica de la corporalidad, la individualidad, la comunidad y la espiritualidad. Asimismo, se arrastran otras cuestiones fundantes que son en esencia territoriales y propias del devenir de la lógica republicana nacional: (a) la aplicación de la ley como acto de hegemonía institucional y de sometimiento; (b) la subyacencia de un contrato social que opera como compromiso de cobertura de las prestaciones del Estado como realización funcional del mismo; y (c) un proyecto colectivo, cooperativo y solidario inter-territorio, con funciones formalmente igualitarias como fundamento de la totalidad simbólica cultural.
Sin embargo, como lo demuestra la evidencia empírica, se debe destacar que el Estado no es equivalente a la acción misma, pues se concretiza a través de la presencia y acción de sus funcionarios, que son los que comunican, llevan o ejecutan la política pública. No es el Estado per se; lo es en cuanto es capaz de movilizar y desplegar capacidades institucionales y operativas para dar cobertura al contrato social subyacente a la premisa de la unidad, lo que debe ser refrendado en su soporte: el espacioterritorio, que es también la representación del límite. Ello requiere de la acción permanente y renovada de la institucionalidad del Estado nacional, el mercado nacional y la sociedad nacional, ya que se deben hacer coincidir expectativas ciudadanas territorializadas con la administración del Estado y su despliegue, como práctica de corresponsabilidad solidaria. El móvil, debe ser la búsqueda de integración regional sobre la base de relaciones no excluyentes, pero dotadas de sentido territorializado a través de acciones conducentes al bienestar.

Dicho lo anterior, el territorio es el espacio culturalmente apropiado y valorizado simbólica e instrumentalmente por las comunidades, es decir, representado y usado en función del trabajo y las actividades cotidianas, por lo que es fuente de subsistencia y de recursos. Es paisaje, apego afectivo, lugar de inscripción de un pasado (Giménez 2000:93). Es a posteriori del espacio; "es lo que se hace", "posee", "codicia" y "aspira" a estar sujeto a control (Nogués 1990); revela políticamente un imaginario como "campo de posibles" para éste, que constituye el fundamento de la intervención y su producción, que su forma sea propio de disputas, de relaciones, hegemonías y construcción de sentido como "orden espacial de la existencia humana... que reflejan y configuran el ser en el mundo" (Soja 1993:101-102). Ello es lo que pone a la vista el espacio, el poder y la frontera (Giménez 2000; Soja 1993; Nogués 1990). "La naturaleza o el espacio pueden ser concebidos sin límites, pero los territorios habitados y apropiados sí los tienen" (Barabás 2004:148). De este modo, como sostiene Cairo (2001:29): "un mapa no reproduce el mundo, lo construye, y, más aún, naturaliza determinados hechos culturales".

Un territorio -como el patagónico- no solo ofrece lo que pudiésemos llamar recursos escasos sino construcciones y cargas simbólicas que ponen límites al convertirlos en lugar que gira sobre una coordenada oeste-este, representando cartográficamente las relaciones y tensiones entre lenguajes técnicos representacionales sur-norte y prácticas territoriales. Se realizan formalmente en él las presunciones del ideal democrático moderno, así como la coincidencia y desajustes entre la arbitrariedad del mapa y la experiencia, entre la entidad política y la entidad 
cultural, entre lo fijo y el movimiento. Mientras la línea contiene lo que será permanente, es decir, fortalece controles internos y externos, proyecta y espacializa la hegemonía etnocrática, la experiencia local del movimiento puede estar en mayor o menor medida dominada, protegida o tensionada en la cotidianeidad al no verse escuchada y representada en la discusión pública, la política pública y las acciones de los funcionarios, ya que conforme a su visibilidad y articulación están operando fuerzas retentivas, expulsoras o atractivas que vuelven elásticas las fronteras. Y, ello es reflejo de conflictos en la dimensión material y económica, como en la identidad y la ética como ámbitos de adscripción.

La movilización política y la participación social de las comunidades, especialmente de las más distantes, de difícil acceso y baja conectividad, está asociada a cuestiones estructurales, la cercanía de fronteras externas y a la misma contingencia, enfrentándose el Ejecutivo a una variable intensidad de validación y de posible protesta conforme a la provisión de bienes y servicios propios de un contrato social ${ }^{7}$. De este modo, la identidad genealógica y hegemonía predicativa se enfrenta al juicio de las comunidades perdedoras e interpeladas en el valor del sentido de pertenencia distribuido territorialmente. Cuestión distinta a una alternativa de etno-pluriterritorialidad como sostén de la identidad, la que es distinta del mapa político.

En este sentido, Augusto Pinochet que había tenido destinación militar al sur de Chile, señala en una conferencia en 1993:

Defino, para una mejor claridad, a las fronteras interiores como aquellos espacios terrestres -bajo la soberanía de Chile- no vinculados total y efectivamente a la acción del gobierno central y/o regional, donde se dificulta el desarrollo de las actividades humanas y productivas, por su distancia del núcleo vital y geo-histórico del país; la ausencia de vías de comunicaciones; la influencia económica y cultural extranjera y la percepción ciudadana colectiva -en cada uno de esos espacios geográficos- de constituir un ente diferente, separado y/o postergado del resto de la población nacional y que no alcanza a disfrutar del bienestar general debido a factores geográficos adversos ${ }^{8}$.

Su tesis es adecuada desde la lógica geopolítica y desde el mapa como soporte; sin embargo, y a pesar del esfuerzo comprometido en la construcción de la falsamente atribuida ruta Longitudinal Austral, que constituye un camino nuevo en lugares desconocidos y casi sin pobladores, los mecanismos de circulación históricos de las poblaciones, así como los mecanismos de expulsión, permanecen inalterables.
En el año 2012, hasta el parlamento debió pronunciarse respecto de la protesta acontecida en la región de Aysén, como lo indica el Oficio $\mathrm{N}^{\circ} 172 /$ SEC/12 (6 de marzo de 2012), emanado por el Senado al Presidente de la República donde se reiteran algunos de los móviles del conflicto: "El menoscabo de los pescadores artesanales, por la pesca sin control que se hace desde las otras regiones, la precariedad de los funcionarios públicos y municipales, respecto a otras entidades del Estado, como Fuerzas Armadas, Poder Judicial, carabineros y médicos, y la falta de condiciones de accesibilidad hacia el resto del país, en que se debe utilizar territorio argentino o transporte marítimo, sujeto a cupos, itinerarios o condiciones climáticas, y algunas embarcaciones inseguras, todas éstas de alto costo, nunca equivalentes a la movilidad que se tiene en el resto del país".

La poca visibilidad del país interior, de los poblados y centros urbanos de frontera en sus urgencias, expresado en tiempo cronológico (satisfacción de la demanda) y existencial (vida cotidiana), obliga a que las localidades y zonas no ganadoras o no integradas -a condiciones de justicia y equidaddeban necesariamente buscar alianzas con sectores académicos, ambientalistas y sensibilidades políticas para tener tribunas comunicacionales, o inclusive alzar una bandera argentina como expresión máxima. $\mathrm{La}$ posibilidad de que los conflictos sociales y ambientales sean visibilizados, está en que éstos lleguen a tener manifestaciones de descontento y solidaridad en la capital -que concentra más del $40 \%$ de la poblacióno que localmente se afecten actividades colaterales propias del gobierno central (paralizaciones, tomas, bloqueos). Si no aparecen en las pantallas no existen, por lo que en la frontera interior un problema social no constituye problema público.

\section{Fronteras Internas e Insularidad Patagónica}

Sin sostener determinismos geográficos, en unos $4.200 \mathrm{~km}$ lineales, y marcado por la cordillera de los Andes, el océano Pacífico, el desierto de Atacama y los campos de hielo sur y norte, se ha generado una condición insular desde el punto de vista de las fronteras. Internamente se vive una condición particular desde la perspectiva de la integración interterritorial, la geografía, las comunicaciones, los desplazamientos, la economía, lo social y lo cultural, incubando la figura de fronteras propiciadas por jerarquización de territorios a través de la inversión en obras públicas y privadas, y las densidades demográficas que aseguran las "rentabilidades sociales".

En este nivel, las fronteras internas son resultado de elaboraciones históricas como los procesos de colonización, la definición de las redes de caminos, la 
extensión del ferrocarril, los puertos, aeródromos y las infraestructuras de almacenamiento, que responden a lógicas temporales y hegemonías discursivas, que califican cuestiones ligadas a una dotación inicial y relativa de recursos naturales y factores productivos, que corresponden a las áreas estratégicamente importantes, menores o inexistentes dentro del mapa.

La Subsecretaría de Desarrollo Regional (SUBDERE), reconociendo las dificultades propias del heterogéneo, disperso y a la vez concentrado poblamiento de Chile, a través de una matriz de oposición y medición aislamiento-integración, define -al igual que Pinochet- la condición de frontera interior como aislamiento, en función del acceso a un conjunto de servicios. Señala, considerando la provisión de servicios, que: (a) una localidad aislada corresponde a la relación existente "entre los componentes de Aislamiento Estructural" (variables morfológicas, clima y División Político Administrativa); (b) "que su Grado de Integración corresponde a la capacidad que tiene el sistema regional para atenuar estas condiciones desventajosas y lograr niveles de integración que permitan que los territorios sobrepasen, aminoren o mitiguen las condiciones de aislamiento, y puedan acceder a las dinámicas y servicios sociales, económicos, políticos, y cívicos, entre otros de los que gozan la mayoría de los habitantes del país" (SUBDERE 2012:11-12). En la misma dirección, Correa y Salas mencionan Zonas Extremas o Especiales, refiriéndose "a territorios que se caracterizan por niveles de aislamiento crítico, población escasa y altamente dispersa, con presencia deficitaria del aparato público y bajo nivel de desarrollo socioeconómico" (Correa y Salas 2015:13). Por lo que, "en la medida que se habita una localidad con condiciones de aislamiento, se está en presencia de una situación desventajosa en relación a otras localidades y territorios del país" (SUBDERE 2012:7).

Con este reconocimiento, en un análisis de más de 3.600 localidades por parte de la SUBDERE, en las fronteras tenemos economías de escala, economías de urbanización y economías de localización. De modo que, la configuración regional desde la perspectiva externa como interna sería el balance de las fuerzas y los efectos operantes que determina un conjunto de coberturas concentradas, débiles o inexistentes que limitan los repertorios de posibilidades de las comunidades dentro del contractualismo tradicional. Y, uno de los efectos evidentes, quizá el mayor en términos formales, es el de la participación democrática: el proceso de aportación libre de los ciudadanos a la conducción política.

\section{Chile: un Archipiélago de Islas Continentales y No Continentales}

Precisamente, la condición descrita es la que nos permite reflexionar en torno a la siguiente tesis: Chile, aunque constitucionalmente posee un régimen político unitario e indivisible, etnográficamente y etnológicamente tal condición parece una búsqueda infructuosa cuando se analiza la distribución de los bienes sociales, la riqueza, los sistemas de oportunidades y las percepciones y reclamos ciudadanos. Más aún, la evidencia -a través de una serie de conflictos socio-ambientales (INDH 2012)demuestra que el país está constituido por un conjunto de islas continentales y no continentales con desigual posibilidad de ser escuchadas y que fragmentan el imaginario de la unidad nacional, las que constituyen las fronteras internas propias del déficit de agenciamiento del Estado en términos territoriales o la falta de confianza en él. Por tanto, una revocación de este modelo, hace necesaria una transformación estructural de los fundamentos del Estado, una revisión de los derechos que consagra la Constitución sobre la existencia y el territorio habitado, y una discusión sobre una renta mínima garantizada para permanecer en zonas de aislamiento.

El Estado, por cierto, llegó con tardanza a muchos lugares, como ocurre en la Patagonia. Pero también existen evidencias etnográficas e institucionales que indican que el Estado no acaba de llegar. Argumentos existen de todo tipo para avalar tal aseveración: (a) determinismos geográficos, (b) precariedad del Estado en términos de disponibilidad de recursos, (c) estigmatizaciones espaciales sobre bio-regiones, (d) priorización o jerarquías de áreas de interés. Pero, en lo substantivo, cuando se piensa en el aislamiento como frontera, existe una ausencia de pensamiento estratégico en términos de Morrisey (1997:13), en la medida que han faltado méritos creativos para generar una perspectiva común en la diferencia; una debilidad en la generación y reflexión respecto de cómo avanzar de manera satisfactoria en la articulación de las acciones asociadas a los subsistemas que permiten hacer la vida dentro de un marco de opciones múltiples conforme a intereses, capacidades, recursos y geografía local.

De este modo, la reflexión sobre las fronteras internas es un tema infinitamente productivo, especialmente en términos de la justicia territorial como pluriterritorialidad. Y lo es más en la actualidad en la perspectiva de la globalización como condición glocalizada (Robertson 2003), es decir, de afectación de fuerzas visibles e invisibles, y estímulos diversos en intensidad que pueden simplemente ubicarse de 
manera a-espacial y sin conexión -aparente- con lo local, aunque pueden reformular el sistema de acciones local a través de nuevas formas de control del territorio. Nos parece por tanto, que al hablar de fronteras la discusión obligada es sobre gobernabilidad, gestión, transparencia, rendición, derechos, desarrollo y seguridad como protección, todas cuestiones propias de una lógica política interterritorial, "porque [en Chile] el carácter de la unidad del Estado y la calidad de la ciudadanía varía funcional y territorialmente" (García 2015:31). Y, como hemos indicado más arriba, la dimensión pedagógica que marca la línea de frontera, está severamente cuestionada en lo formal y lo empírico.

Entonces, por una parte se debe comprender la diferencia radical entre los aspectos territoriales y funcionales de la política, ya que mucho de lo que acontece en el territorio de manera localizada es la concreción del poder que permite la validación de las preferencias de los ciudadanos (i.e. votos); así como también se juega de manera prioritaria en las áreas de frontera interior y límites con los países vecinos, la identidad y reconocimiento mutuos que se otorgan gobernantes y gobernados". Por otra, porque "el territorio no es un soporte pasivo de localización potencial sino el medio activo en el que los actores desarrollan redes de cooperación e intercambio, originando la innovación y la creatividad" (Artesi 2007:349). Y, en el caso de la Patagonia, aparece un país desconocido en el centro político: el país de habitus horizontal; el del ir y venir en el cotidiano para la visita médica o traer alimentos, con invernadas y veranadas a uno u otro lado de la cordillera, con redes de trabajo transfronterizas, con filiaciones políticas y consanguíneas existentes desde siempre.

Las fronteras interiores (también áreas o zonas especiales) realzan las asimetrías regionales, la concentración de oportunidades y distribución de bienes sociales, que privilegian las áreas metropolitanas centrales y las regiones exportadoras.

\section{Villa O'Higgins: el Simbolismo del Prócer en el Abandono o en el Exilio}

Villa O’Higgins queda al final del camino. Está al final de la Carretera Austral, cerca de los Campos de Hielo Sur; y, antes del mes de noviembre es difícil llegar. Los turistas que arriban con el estío colman la oferta de albergues rápidamente, agotan los pasajes para embarcarse en Puerto Bahamondes a navegar el lago y visitar glaciares, y, si tienen vehículos adecuados cruzan a Argentina, o se regresan por los interminables kilómetros de ripio, cuestas y curvas por donde llegaron. En el lugar viven unas 600 personas, con un único establecimiento escolar que solo permite completar la educación básica, y que obliga a emigrar al norte a quienes califican y tienen los recursos para continuar estudiando, con altos índices de deserción escolar ${ }^{10}$, con internet precario, con "caja vecina" como único servicio bancario, con una primera bomba de bencina instalada a partir del 2014. Cuando no hay combustible, se paraliza todo: transporte y calefacción. Faltan los insumos básicos: "se come lo que llega"; "hoy nos queda una porción de pollo, y dos trozos de carne... pueden ser con arroz o papas. No hay más" (registro realizado en diciembre de 2015). Villa O'Higgins es la frontera interna, y la gente así lo retrata: “... la vida es muy dura. La soledad mata; pero, se vive tranquilo"; "esto toma vida, los negocios tienen movimiento mientras dura el verano. Hasta los alojamientos se hacen pocos" confiesa un lugareño, un empresario local reflexionando en que quedan pocas semanas para el fin de la temporada (registro realizado en febrero de 2015).

Mientras se discutía en el Congreso, en Valparaíso, una ley que "podía" autorizar la venta de fármacos genéricos en supermercados, a $1.720 \mathrm{~km}$, en Villa O'Higgins (latitud: $49^{\circ} 20^{\prime}$ Sur Longitud: $72^{\circ}$ 18 ' Oeste, y $265 \mathrm{msm}$ ), la comuna más austral de la región de Aysén, sus habitantes no contaban con farmacia y supermercado, y la ronda médica se realiza cada 15 o 30 días, sólo si las condiciones climáticas lo permiten ${ }^{11}$. La Villa fundada en 1966, que lleva el nombre del "padre de la patria", corresponde al único núcleo poblacional de la zona. Se llega por la carretera austral (ruta G7), un camino ripiado que en algunos casos no supera los siete metros de ancho. La apertura de la ruta de penetración la ejecutó el Cuerpo Militar del Trabajo a partir de 1976, con un contingente de varios miles de trabajadores, soldados, conscriptos y jefes de hogar desempleados bajo un subsidio a la cesantía (Plan de Empleo Mínimo), más oficiales y profesionales. A la fecha se extiende por 1.250 km, hasta Villa O'Higgins, a unos $775 \mathrm{~km}$ al sur de Puerto Montt (en línea recta), con $260 \mathrm{~km}$ de caminos laterales, de un total que se espera completar de $2.175 \mathrm{~km}$ hasta Puerto Natales, en Magallanes.

Las localidades más cercanas son Caleta Tortel (500 hab.) a $150 \mathrm{~km}$, Cochrane (3.000 hab.) a $230 \mathrm{~km}$ y El Chaltén, Argentina a $110 \mathrm{~km}$, cruzando el lago O’Higgins y Laguna del Desierto. La ciudad más cercana es Coyhaique, la Capital regional de la región de Aysén, con una población superior a las 59.000 personas (según proyecciones censales) y localizada a $571 \mathrm{~km}$. de distancia, que implica dos días de viaje. Ahí se encuentra el hospital base y pueden satisfacerse algunas de las demandas de salud ${ }^{12}$. En Villa O'Higgins, como en todas las localidades rurales de la Patagonia, se conocen solo dos enfermedades: "las que se curan en casa, y las que matan". Cuando 
se trata de vender los animales, base de su actividad económica, una barcaza en el Lago O'Higgins, en el lado chileno, y San Martín en el argentino, pasa una vez al año. Villa O'Higgins es frontera con Argentina, y su puesto fronterizo en el paso El Bruna fue desalojado, lo mismo que el Marconi, y el retén [de carabineros] Laguna Redonda fue desocupado en el año 2000. El paso Río Mayer (ribera norte), el paso Río Mosco, el paso Lago O'Higgins - San Martín, el paso Marconi y el paso Dos Lagunas, no tienen complejos fronterizos y Carabineros opera en función de aduanas. También está desconectado de "El Chaltén", el poblado fronterizo espejo, uno de los lugares más exclusivos de turismo de élite, considerado por algunos "la capital mundial de trekking", y donde turistas cruzan la frontera sin ningún control (Diario el Mercurio, 22 de junio de 2013).

La crónica periodística, que luego dio lugar a reportajes televisivos, es elocuente. Distancia, aislamiento y carencias diversas; un sorprendente “otro Chile". Un registro de campo (Villa O'Higgins 2015), refuerza esta idea: "Chile llega hasta Puerto Montt en forma clarita, después empieza algo raro hasta Punta Arenas". El testimonio se sustenta en la ausencia de coordenadas territoriales que permitan una imagen extendida del territorio como soporte de una continuidad, ya que no existe la idea de kilómetros lineales en la Patagonia, porque éstos son substituidos por horas aproximadas y tentativas de viaje. Como sostiene el handbook Lonely Planet de los viajeros: la seguridad de un viaje en bus, solo está asegurada cuando uno confirma en la ventanilla de la terminal de autobuses la salida ${ }^{13}$. El recorrido por la región de Aysén solo es posible si las condiciones climáticas lo permiten, y si los ripiados caminos no están cortados por la crecida de un río, una nevada, la caída de un árbol o el desprendimiento de parte de un cerro.

Los embarques que llegan a la región proveniente del centro del país, arriban a Puerto Chacabuco, un pequeño puerto de carga para una región que tiene 91.492 habitantes y $108.494 \mathrm{~km}^{2}$, equivalentes al 14,3\% del territorio nacional. Desde ahí los camiones con suministros deben recorrer casi $600 \mathrm{~km}$, para luego aguardar uno de los tres viajes semanales en verano, o los dos en invierno, que realiza la barcaza para cruzar el Fiordo Mitchell y llegar a Villa O'Higgins. Tras unos 50 minutos de navegación, otros $100 \mathrm{~km}$ deben avanzar por un camino angosto para recién llegar a la comuna más austral de la región, flanqueada por el límite de la experiencia viajera nacional: Campo de Hielo Sur ${ }^{14}$.

Por cierto, la distancia y el transporte son parte de los altos costos de vida, como el que implica contar con un bidón de gas en una localidad donde las temperaturas oscilan en invierno entre $-15^{\circ} \mathrm{C}$ y $8^{\circ} \mathrm{C}$. Prácticamente en todas las localidades interiores los productos aumentan su valor hasta en $150 \%$ en relación a Coyhaique. Es decir, el valor del flete supera el valor del producto, mayormente cuando se trata de insumos para construcción. Así, la sumatoria de carencias, es lo que configura una distancia simbólica y material en las zonas australes en relación al centro del país, ya que hay un rezago estructural, un déficit político, económico, de servicios y de profesionales, porque las rentabilidades sociales solo se miden por costos, número de habitantes y votos válidamente emitidos.

Entonces, los habitantes viven una bipolaridad para dar forma a su existencia. Cuando requieren de un servicio o tienen una necesidad que obliga a desplazamiento territorial: ¿van a Chile o Argentina como entidad política?; o, afirmativamente en términos de referencia simbólica y habla: "van a Chile (al norte), o "van a Argentina" (al este). No hay respuesta única; las informaciones radiofónicas de Argentina son tan importantes como las de Chile, y son tan valiosos los pesos argentinos como los chilenos.

\section{Magallanes y Aysén: Lejos de Chile}

Magallanes y Aysén son las regiones australes que reclaman al centralismo político su indiferencia dentro de una asignación presupuestaria de tipo mercantilista, que condiciona la asignación de recursos en función de su demografía, a pesar de la inmensa riqueza que pueden representar en el imaginario verde del mundo. Sintéticamente, se trata de regiones perdedoras: viven de los subsidios del Estado de Chile, del empleo público (civil y militar), obras públicas como la construcción de la carretera Austral (Aysén), y no pueden administrar su propia riqueza. Sus hospitales no cuentan con especialistas, escuelas y universidades de calidad, servicios de transporte eficiente e infraestructuras culturales. Su economía ha sido de enclave y de cortos ciclos. En Magallanes explotación aurífera, ovejas con fines lanares e hidrocarburos; en Aysén, primero ovejas; ahora salmoneras, hidroelectricidad, torres eólicas y forestales.

Las actividades han tenido ciclos muy cortos, a pesar que los imaginarios locales y predicativos nacionales hayan quedado anclados en estas labores productivas. Sin embargo, lo señalado instala una cuestión básica: la unión entre la voluntad política o la afirmación política y la ciencia y sus aplicaciones territoriales. Esto, como señala Boisier (2006:149$150)$ porque se generan "lugares productivos discontinuos", porque el territorio se constituye de manera diferenciada, inclusive al interior de las propias regiones.

En toda la zona patagónica se habla de manera corriente de "ir a Chile", cuando se va hacia el 
norte, es decir, a Puerto Montt como referencia, a $1.000 \mathrm{~km}$ de Santiago, la capital. El registro revela un enclaustramiento y discontinuidad en términos de movilidad y de limitadas referencias circulantes para hacer la vida, lo que deviene en una situación de distancia afectiva; un sentimiento de un país diferente, que arrastra la idea de lejanía y abandono como cuestión permanente: es "estar aparte", "de ser una región lejana", "un país distinto", "es vivir en una isla que te ahoga", "hay que vivir el invierno aquí, para saber lo que es vivir en la Patagonia. Esto te inmoviliza", "aquí no hay nada... si no te mueves, a los dos meses te quieres volver" (registros realizados en Coyhaique, en julio de 2016). Una maestra rural relata en La Tapera: "los sueldos son atractivos para venir a trabajar acá, pero la lejanía te pasa la cuenta en términos de familia y desarrollo profesional; y eso se hace cada vez más duro"; otro docente agrega: "leo tres libros al mes, con ello evito que el campo me atrape". Y, un alcalde confiesa: "aquí no elegimos a los profesores; llegan los que se animan a venir. No podemos decidir nada" (registros realizados en la Tapera, en julio de 2016).

El sentimiento configura una multiplicidad de identidades mínimas, anónimas y únicas alojadas en el Chile interior patagónico, apareciendo etnográficamente la idea de islas no conectadas entre ellas, aunque constituyen un gran archipiélago. Por ello, hemos registrado en nuestras entrevistas que cuando se sale a estudiar hacia las regiones del centro del país, "se descubre un mundo nuevo", "el sol y la calle, la vida al aire libre"; "se descubren las librerías, los cines, los espectáculos"; "se hace cada vez más difícil volver... y cuando vamos [a ver a la familia], uno se quiere regresar... ya siente que los amigos no son los mismos. Por eso, a veces uno se inventa que tiene que estudiar en enero, pero la verdad es que uno no quiere volver" (registro realizado en Coyhaique, en 2015 a un profesional recién titulado). Y, conforme a su socialización resulta casi natural -tanto en Magallanes como en Aysén- la siguiente disyuntiva al terminar la educación secundaria: "ite quedas o te vas?"15.

De este modo, es sólo con el afianzamiento tardío de los hitos fronterizos hace 50 años, tanto por parte de Gendarmería en Argentina y Carabineros en Chile que custodian las fronteras, que la alteridad como nacionalidad se ha constituido en una preocupación efectiva, aunque sin resultados. No obstante ello, en algunas localidades fronterizas, por la existencia de redes familiares a ambos lados de la frontera, el límite y la nacionalidad para muchos habitantes es casi una formalidad, porque con el proceso de circulación laboral o comercial, coincidentemente según los funcionarios municipales de la Comuna de Futaleufú (enero de 2014) y Palena (enero de 2014): "algunos siempre reclaman derechos y beneficios en los dos países. Hay muchos que tienen tierras allá y acá, y residen en los dos países".

El nacionalismo castrense propició iniciativas integradoras, como el desarrollo temprano de la aviación a cargo de la Fuerza Aérea desde 1930, creando una red de aeródromos en toda la Patagonia, convirtiendo al avión en el medio de transporte característico de un extenso territorio, frente a un poblamiento sin ferrocarril ni carreteras. La aviación fue una alternativa para atenuar la desconexión y el abandono, ofreciendo una forma más barata de conectividad y medianamente efectiva para una población escasa y dispersa. Sin embargo, ha tenido sus propias limitaciones, pues los únicos aeropuertos grandes y operables todo el año, se consolidaron en los espacios planos más próximos a las ciudades de Coyhaique (Aysén) y Punta Arenas (Magallanes). El resto del territorio vio proliferar una vasta red de aeródromos que se ha constituido en la más densa de todo el país: el 45,8\% del total nacional de estas estructuras se concentran en la Patagonia (Dirección de Aeropuertos, 2013), aunque la operatividad se ubica en un $50 \%$ anual.

Conforme a lo señalado, los elementos culturales y de identidad atribuidos a una nación son difíciles de pesquisar cotidianamente en grandes extensiones de la Patagonia chilena, por lo que claramente existen diferencias al aludir a la "chilenidad" entre lo estatalnacional y lo territorial como circuito localizado en territorios de frontera y zonas aisladas, ya que no coinciden Estado, nación y territorio como unidad de frontera. Así, la percepción de dónde empieza y dónde termina el país, es una cuestión muy reciente, así como la misma idea de pertenecer a él. A pesar de haber existido hipótesis de guerra con Argentina, las comunas cordilleranas de Chile de la provincia de Palena generan un circuito binacional eficiente con Esquel y Trevelin; Coyhaique con Río Mayo, Comodoro Rivadavia y Puerto Madryn; Chile Chico con los Antiguos; y, Punta Arenas con Río Gallegos (Figura 3).

Más aún, como corolario, todos nuestros registros de campo indican que hasta los años sesenta, en el poblado cordillerano de Futaleufú, Carabineros informaba a los habitantes -como mandato en términos de producción de sentidos- "en qué lugar de la frontera se encontraban", que "debían elegir entre ser chilenos o argentinos" y "en qué dirección se encontraba cada país" (entrevista a un funcionario de Carabineros jubilado, 2014), como si las personas estuvieran plena conciencia de la geografía política y en condiciones de establecer diferencias substantivas a partir del habitar y su movilidad. Hasta esos años, "uno podía tener los animales domésticos en Argentina y 


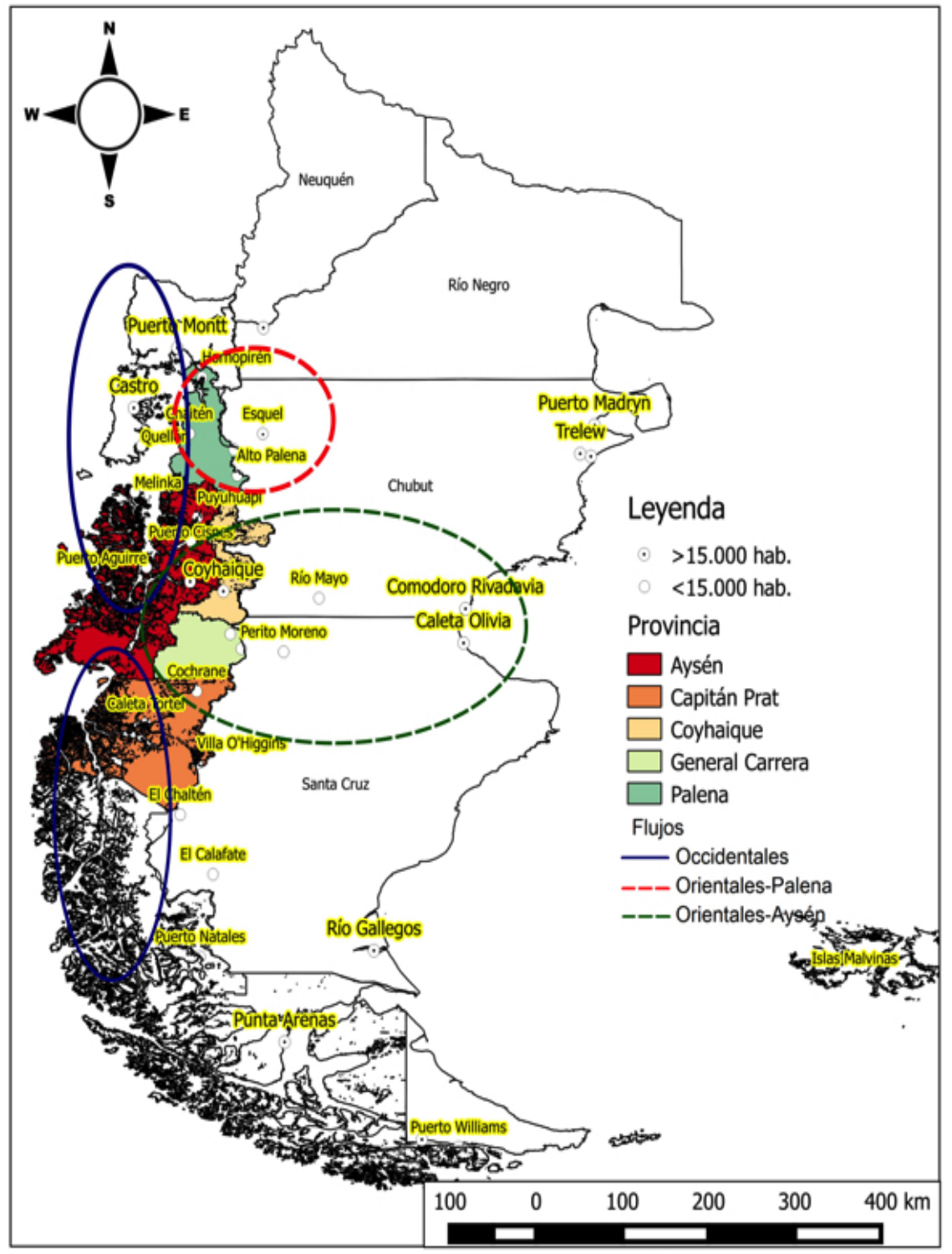

Elaboración: Juan Sáenz, 2015

Figura 3. Flujo de movilidad e intercambio en la Patagonia NorCentral. Mobility and exchange flow in north central Patagonia. 
la leña en Chile, y uno qué sabía, si estaba dentro de su propiedad" (en Futaleufú, 2013); casi todos los contactos, interacciones y la cultura "eran argentinas" (i.e.simbolismos en el vestir y el habla), por lo que entenderá que cuando fue necesario afianzar hitos y deslindes limítrofes internacionales, recién estas poblaciones obligaron al gobierno central a iniciar contactos regulares con estos poblados fronterizos, para "chilenizarlos" y hacer soberanía, ya que "la nación queda lejos” (Núñez 2017).

Cuando en el Valle de California, donde la frontera está separada por un río, existen personas que siendo "chilenas", o sintiéndose tales, reconocen "haber realizado el servicio militar en Argentina”, la operación misma de adscripción a una nacionalidad es artificial, porosa y deja de tener sentido. Prima la epistemología geocultural; la que define un límite físico que otorga simultáneamente espesor a la identidad como igualdad y diferencia. Mientras, y así lo creemos, la condición fronteriza es la de una "configuración" en términos de Norbert Elías (1979); zonal, binacional, de interacciones y dependencia recíproca.

\section{Conclusiones}

El que la carretera austral (ruta G7) no lograra completar la conexión por tierra, con un camino susceptible de usarse todo el año, y con un estándar adecuado para el transporte más expedito como la Ruta 40 en el lado argentino, que con más de 5.000 km une al país entre la frontera con Bolivia y el Estrecho de Magallanes, explica algunas de las dificultades que hemos señalado entre límite, frontera, soberanía (s), identidad y país interior. La discontinuidad de la conectividad es una hipótesis más para explicar el fracaso de la definición territorial de la Patagonia chilena y se mantenga como la frontera interior o la "tierra de entre medio", frente al desarrollo económico neo-capitalista y tecnocrático. Su aislamiento permanente propició el estancamiento demográfico, con una cadena de efectos perversos: escasez de mano de obra calificada y profesionales, y falta de desarrollo de oficios urbanos; pobreza en el mercado de alimentos, bienes y servicios accesibles; transporte caro para sus habitantes, crecimiento urbano reducido, centralizado y despoblamiento de grandes extensiones rurales. Téngase presente la fragilidad territorial a través del caso del poblado de Chaitén, en Palena, después de las épicas protestas y demandas para su refundación asociadas a la catástrofe del 2008. La puerta de entrada a la Patagonia Austral, en términos demográficos se contrajo, porque su población, con las temporalidades emocionales, políticas, académicas y económicas comprometidas en el proceso, descubrió en su dispersión otros repertorios de posibilidades (Mandujano et al. 2016).
Si en el pasado, estas tierras de "entre medio" hubo de ser administrada, generar fomento, ofrecer seguridad y colonizar, mucho de ello parece pendiente en esta historia -de algo más de cien años- amputada y con omisiones. Antes, a la distancia: ¿qué podía ser resuelto con eficacia?. Todo estaba lejos. Ahora, aparentemente más cerca: ¿qué puede ser cumplido con eficiencia dentro del contrato social del Estado? La comprensión de la frontera como binacionalidad y movimiento, sigue concibiéndose como un problema técnico y no cultural por el mundo político.

Existe un país interior y una frontera interior porque hay un deficitariomilieu, es decir, condiciones políticas, sociales, culturales e institucionales que conecten con el imaginario nacional y su hegemonía predicativa. Con ello, es evidente que se trata de una frontera interior. La debilidad regional en la Patagonia está en la incapacidad de reunir a través de la acción del Estado y sus funcionarios un conjunto de elementos propios de un desarrollo territorial que permita elevar la calidad de vida, relativa a cuestiones como: (1) el bienestar; (2) la sostenibilidad; (3) la gobernabilidad y participación local; (4) la defensa de la identidad y el desarrollo; y, (5) el ordenamiento del territorio para generar arraigo y constituir polos de atracción. En estos territorios, lo público debe ser asumido por la gente y el Estado.

El desarrollo territorial integrado y un proyecto colectivo requieren de equidad territorial y solidaridad interterritorial. Una conjunción de estas variables y procesos descentralizadores podrían ayudar a disminuir el sentimiento de "ser otro desvalorizado" en relación al resto del país. Las fronteras interiores como las de Aysén y Palena refieren a un país inarmónico y de una desigualdad ideológica, jurídica, política, económica y cultural. Las limitaciones de las poblaciones que habitan el país interior, es decir, la frontera dentro de la propia frontera, terminan por hablar de una población y un territorio imbuido dentro de unos marcos con pocas alternativas de diferenciación interna, y con gran dependencia externa. Las deficiencias en la conectividad y el alto costo para salir y entrar a estos territorios, y los problemas para los desplazamientos internos son la evidencia más tangible de la supervivencia de la frontera de principios del siglo XX y de mecanismos permanentes de expulsión y de una condición monocromática en el paso del tiempo.

Es necesario aumentar la descentralización del poder en el territorio nacional y regional. La descentralización es una de las herramientas de articulación para implementar nuevas políticas de integración, que permitan autonomía de acuerdo a los recursos naturales y materiales, porque ayudaría a 
traer procesos de democratización y nuevas formas de participación de la ciudadanía. He ahí, una aspiración y constatación paradójica.

Agradecimientos: Este trabajo es resultado del proyecto de investigación Fondecyt 1120795, "Etnografía de la colonización y recolonización en los territorios de frontera de Chiloé Continental. Actores, intercambios y conflictos", y 1161013, "De los ensamblajes locales, regionales y nacionales a los ensamblajes globales. Etnografía y política de las relaciones de sujeción local en el área de influencia de la Carretera Austral, la provincia de Palena y la región de Aysén". Agradecemos al programa Fondecyt haber apoyado estas investigaciones, así como a los evaluadores y su disposición, cuyos acertados comentarios y sugerencias permitieron mejorar este artículo.

\section{Referencias Citadas}

Anderson, B. 2006. Comunidades Imaginadas. Reflexiones sobre el Origen y la Difusión del Nacionalismo. Fondo de Cultura Económica, México, D.F.

Artesi, L. 2007. Desarrollo local y turismo. Notas sobre nuevos enfoques teóricos y metodológicos para la implementación de políticas en la Patagonia Austral. En Ciudadanía y Territorio y Desarrollo Endógeno. Resistencias y Mediaciones de las Políticas Locales en las Encrucijadas del Neoliberalismo, coordinado por R. Zárate y L. Artesi, pp. 347-361, Editorial Biblos, Buenos Aires.

Baeza, B. 2009. Fronteras e Identidades en la Patagonia Central (1885-2007). Protohistoria Ediciones, Rosario.

Bandieri, S. 2011. Historia de la Patagonia. Editorial Sudamericana, Buenos Aires.

Barabás, A. 2004. La construcción de los etnoterritorios en las culturas indígenas de Oaxaca. Desacatos. Revista de Antropología Social 14:145-168.

Benedetti, A. e I. Laguado 2013. El espacio fronterizo argentinochileno. Definición de categorías operativas y primera aproximación descriptiva. En Fronteras en Movimiento e Imaginarios Geográficos. La Cordillera de los Andes como Espacialidad Sociocultural, editado por A. Núñez, R. Sánchez y F. Arenas, pp. 451-483. PUC, Instituto de Geografía y RIL Editores, Santiago.

Bhabha, H. 1996. Culture's In-between. En Questions of Cultural Identity, editado por S. Hall y P. Du Gay, pp. 53-60. Sage, London.

Boisier, S. 2006. Imágenes en el Espejo. Aportes a la Discusión sobre Crecimiento y Desarrollo Territorial. Editorial Puerto de Palos, Santiago.

Bonfil, G. 1990. México Profundo. Una Civilización Negada. CONACULTA-Grijalbo, México, D.F.

Cairo, H. 2001. Territorialidad y fronteras del Estado-nación: Las condiciones de la política en un mundo fragmentado. Política y Sociedad 36:29-38.

Carreño, L. 2003. Los sucesos de Chile Chico, 1917-1918. Un episodio del poblamiento de Aisén. Revista de Historia Social y de las Mentalidades 7:121-147.

Chatterjee, P. 2008. La Nación en Tiempo Heterogéneo y otros Estudios Subalternos. Siglo XXI- CLACSO, Buenos Aires.

Cheyre, J. 2012. Entrevista. Santiago: Radio Universidad de Chile. Consultado en: http://derecho.uc.cl/Derecho-UC-en-los-medios/ profesor-juan-emilio-cheyre-analiza-el-conflicto-de-aysen-enradio-universidad-de-chile.html
CORFO 1950. Geografía Económica de Chile. Tomo I y II. Santiago.

CORFO 1960. Geografía Económica de Chile. Tomo III y IV. Santiago.

Correa, L. y A. Salas (eds.) 2015. Prefacio. En Gobernabilidad, Desarrollo y Seguridad en las Zonas Extremas. Academia Nacional de Estudios Políticos y Estratégicos, Santiago.

Crespo, C. y M. Tozzini 2013. Fronteras identitarias a la sombra de la gran frontera estatal. Omisiones y tensiones en las construcciones del pasado en la Comarca Andina del Paralelo 42 Patagonia Argentina. En Fronteras en Movimiento e Imaginarios Geográficos. La Cordillera de los Andes como Espacialidad Sociocultural, editado por A. Núñez, R. Sánchez y F. Arenas, pp. 357-386. PUC, Instituto de Geografía y RIL Editores, Santiago.

Dirección de Aeropuertos 2013. Red Aeroportuaria Nacional. Ministerio de Obras Públicas [http://www.aeropuertos.gov.cl/ Paginas/default.aspx : 22 de julio 2013].

Elías, N. 1979. El Proceso de Civilización. Fondo de Cultura Económica, México, D.F.

García, V. 2015. Políticas públicas y zonas extremas en el norte y sur de Chile: aproximaciones desde el marco de las coaliciones promotoras. En Gobernabilidad, Desarrollo y Seguridad en las Zonas Extremas de Chile. ANEPE, Santiago.

Giménez, G. 2000. Territorio, cultura e identidades. La región sociocultural. En Cultura y Región, editado por J. Martín-Barbero, F. López y A. Robledo, pp. 87132. CES/Universidad Nacional/ Ministerio de Cultura, Bogotá.

Harley, J. 2005. La Nueva Naturaleza de los Mapas. Ensayos sobre la Historia de la Cartografía. Fondo de Cultura Económica. México, D.F.

Ibar, J. 1973. Aisén. Hombres y Naturaleza. Imprenta de La Armada, Valparaíso.

Instituto Nacional de Derechos Humanos (INDH) 2012. Mapa de Conflictos Socio-Ambientales en Chile. Santiago.

Ivanoff, D. (sf) La guerra de Chile Chico. http://www. memoriachilena.cl/archivos2/pdfs/MC0012980.pdf

Jocelyn-Holt, A. 2004. Historia General de Chile. 2, Los Césares Perdidos. Editorial Sudamericana, Santiago.

Laclau, E. 2002. Misticismo, Retórica y Política. Fondo de Cultura Económica, Buenos Aires. 
Máiz, R. 2008. La Frontera Interior. El Lugar de la Nación en la Teoría de la Democracia y el Federalismo. Tres Fronteras Ediciones, Murcia.

Maggiori, E. 2012. La Cruzada Patagónica de la Policía Fronteriza. Ediciones Remitente Patagonia, Gaimán.

Mandujano, F., J. Rodríguez y S. Reyes 2016. El Estado y localidades aisladas en la Patagonia chilena: una tensa relación en la última frontera interior de América Latina. Bitácora. Revista Urbano Territorial 26:83-92.

Mandujano, F. y J. Rodríguez 2016. "La catástrofe del 2008 en la provincia de Palena: reflexiones sobre su impacto y particularidades en la Patagonia Occidental. Magallania 44 (2):69-85.

Martinic, M. 2011. Magallanes en el Ordenamiento Territorial de Chile Republicano. Su Expresión Cartográfica (1853-1884) Magallania 39 (2):37-45.

Morrisey, G. 1997. Pensamiento Estratégico. Prentice Hall, México, D.F.

Nogués, J. 1990. Los nacionalismos y la geografía. Geocrítica: 5-39.

Núñez, A., B. Baeza y M.C. Benwell 2017. Cuando la nación queda lejos: fronteras cotidianas en el paso Lago Verde (AysénChile) - Aldea Las Pampas (Chubut-Argentina). Revista de Geografia Norte Grande 66:97-116.

Núñez, A., R. Molina, E. Aliste y A. Bello 2016. Silencios geográficos en patagonia-aysén: territorio, nomadismo y perspectivas para re-pensar los márgenes de la nación en el siglo XIX. Magallania 44 (2):107-130.

Osses, H. 2008. Patagonia. Ficción y Realidad. Zagier y Urruty, Buenos Aires.

Otero, L. 2006. La Huella del Fuego. Historia de los Bosques Nativos. Poblamiento y Cambios en el Paisaje del Sur de Chile. Pehuén, Santiago.

Osorio, M. 2014. Antiguas Historias del Valle Simpson. Nire Negro Ediciones, Coyhaique.
Pinochet, A. 1993. "Ejército de Chile: posibles elementos a considerar en su proyección futura". Conferencia, 19 de agosto. Santiago, Chile.https://fas.org/irp/world/chile/holzmann.htm

Robertson, R. 2003. Glocalización: tiempo-espacio y homogeneidadheterogeneidad. En Cansancio del Leviatán: Problemas Políticos de la Mundialización, coordinado por J.C. Monedero FernándezGala, pp. 261-284. Trotta, Madrid.

Rodríguez, J., N. Gissi y F. Mandujano 2018. Nuevas territorializaciones y justicia social en la Patagonia chilena: una aproximación desde la antropología política. En Etnografías del Poder. Formas Actuales de Dominación en el Mundo Rural, Hernán Salas Editor, IIAUNAM, México, D.F. (en prensa).

Rodríguez, J., N. Gissi y P. Medina 2015. Lo que queda de Chile: La Patagonia, el nuevo espacio sacrificable. Revista Andamios 12 (27):335-356

Sáenz, J. 2016. Territorio Rural y sus Transformaciones ante Procesos de Globalización en la Subregión Transandina de la Provincia de Palena, Patagonia Chilena. Memoria para optar al título de Antropólogo Social, Departamento de Antropología, Universidad de Chile.

Said, E. Orientalismo 2002. Orientalismo. Debate, Barcelona.

Senado de Chile (6 de marzo de 2012), Oficio No 172/SEC/12.

Soja, E. 1993. Geografias Pós-Modernas. A reafirmação do espaço na teoria social crítica. Jorge Zahar Editor, Río de Janeiro.

Subsecretaría de Desarrollo Regional (SUBDERE). 2012. Estudio identificación territorios aislados 2011. http://www.subdere.gov. cl/documentacion/estudio-identificaci\%C3\%B3n-de-territoriosaislados-2011 Descargado el 15 de septiembre de 2017.

Torres, S. 2002 La zona cordillerana del Chubut-Aysén. Una sociedad fronteriza en la primera mitad del siglo XX. Anuario del IEHS, UNCPBA 17:325-346.

Vich, V. 2008. Presentación. En La Nación en Tiempo Heterogéneo y Otros Estudios Subalternos. Editado por P. Chaterjee. Siglo XXI- CLACSO, Buenos Aires.

Worrall, S. 2004. Land of the Living Wind. National Geographic, Jan.

\section{Notas}

${ }^{1}$ La construcción corporativa es una forma de aceptación y autorización de las posibilidades de lectura, así como de su justificación como relación hegemónica y de poder. Entonces, una imagen del territorio como régimen discursivo, ofrece los elementos de diagnóstico, de identificación de problemas y soluciones, así como las metodologías y técnicas de corrección (Said 2002).

${ }^{2}$ Por ejemplo, Susana Torres sostiene que en las primeras décadas del siglo XX, del lado argentino de proveía de ganado vacuno, mientras que desde el lado chileno ingresaban productos manufacturados. También, existían inversiones capitalistas que poseían sus patrimonios en uno y otro lado de la frontera.

${ }^{3}$ Actualmente, los únicos centros poblados son Punta Arenas (1848), Porvenir (1894), Puerto Natales (1911), Puerto Williams (1953) y Cerro Sombrero (1958). La región de Magallanes y la Antártica chilena, posee una extensión $132.291 \mathrm{~km}^{2}$, equivalente al 17,5\% del territorio nacional, y según el Censo de 2002 posee una población de 150.886 habitantes, equivalente al $1 \%$ del total nacional.

${ }^{4}$ Sobre este punto, y como elemento de conflicto y control territorial, Danka Ivanoff (sf) describe el proceso de acaparar tierras y ampliación de la frontera ganadera en Aysén por parte de los controladores de toda la región extrema austral de Chile y Argentina, el que posteriormente da forma a la llamada "guerra de Chile Chico" (1918) o "sucesos del Lago Buenos Aires". Señala que las grandes concesiones que se inician en el año 1901, son resultado de fusiones o traspasos de derechos que quedaron en manos de J. Menéndez, M. Brawn, F. Campos, G. Blanchard y J. Nogueira, quienes litigan sobre ocupaciones de los errantes expulsados de Argentina.

${ }^{5}$ La circulación de los chilenos en la vertiente oriental de la cordillera, está documentada hasta Comodoro Rivadavia, 
tanto en el pasado como en el presente cercano, ya que durante la dictadura cívico militar fue un lugar de refugio para los disidentes y perseguidos.

${ }^{6}$ En otro trabajo (Rodríguez et al. 2015), nos hemos referido ampliamente al lugar que ocupa actualmente la Patagonia en el imaginario de la economía mundial. En éste sostenemos: que es uno de los pocos lugares del mundo donde hay tierras disponibles y fuentes de recursos abundantes, demandados por la economía global. Se le identifica como un lugar no contaminado, con importante biodiversidad, ríos de flujo libre y de gran potencial energético; remoto, poco asequible, con habitantes aislados y distanciados, con servicios deficientes producto del centralismo del Estado nacional. Se identifican, además, distintos actores e imaginarios que están generando una rescritura del territorio con fines diferenciados y contradictorios, como el Estado, los capitales, las comunidades, grupos ambientalistas, migrantes por cambio de estilo de vida y otros con intereses ideológicos.

7 Para el caso de la Patagonia, son esclarecedores el llamado "conflicto de Magallanes" (2011) y el "movimiento social del Aysén" (2012). El primero, precipitado por un alza indiscriminada del gas, decidida en Santiago; y, el segundo, un acumulado histórico que incluía quitar el impuesto específico a los combustibles, sueldos regionalizados, universidad pública regional, procedimientos vinculantes a través de plebiscitos, entre otros.

${ }^{8}$ Años después, Juan Emilio Cheyre, Jefe del Ejército, con una mirada geopolítica habla del fracaso de la regionalización y de la invertebración del país, en la medida que en cuatro décadas no se logró autonomía regional y local ni integración a través de una carretera longitudinal que fue pensada en los años 60, comenzada a construir a mediados de los 70 y que permanece inconclusa en el 2017.

9 Nos referimos concretamente a dos cuestiones centrales que se manifiestan con mayor o menor intensidad ante coyunturas y que son reflejos de malestares regionales que reclaman por el "abandono" o que demandan "tratos especiales": (a) intereses emancipatorios de algunas regiones y zonas como Magallanes, Isla de Pascua y la Araucanía, las que ya tienen emblemas distintivos que coexisten con la bandera y escudo nacional; (b) la presencia de banderas argentinas en áreas de frontera austral.

${ }^{10}$ Solo el 2018 se ha implementado la educación secundaria. Con anterioridad, la única posibilidad de continuar estudios medios era abandonando el poblado, lo que tenía incidencia en aspectos afectivos como el desarraigo, y en lo económico. Es decir, por una parte, los estudiantes debían partir para no volver hasta terminado el año escolar; por otra, implicaba un sacrificio económico difícil de sostener para las familias.

${ }^{11}$ En la región de Aysén, con una población estimada de 107.334 personas al año 2014, la comuna de Coyhaique, capital regional cuenta con 5 farmacias. Aysén la segunda ciudad en importancia, sus casi 30.000 habitantes cuentan con tres establecimientos. Las comunas de Cochrane y Chile Chico, cuentan con un establecimiento. Lago Verde, Cisnes, Guaitecas, O’Higgins, Tortel y Río Ibáñez no tienen. Las farmacias corresponden a una actividad privada.

${ }^{12}$ Los registros de campo y las entrevistas así como la información secundaria habla de déficit profesionales especializados y falta de algunos servicios básicos como una unidad de cuidados intensivos pediátricos. Esto significa que, frente a brotes como influenza, los niños deben ser derivados a centros hospitalarios fuera de la región.

${ }^{13}$ Lo mismo ocurre con las barcazas para cruzar los lagos patagónicos.

${ }^{14} \mathrm{El}$ viaje hasta Villa O'Higgins corresponde a un imperdible para los turistas extranjeros por la belleza de la ruta, y porque después de Groenlandia y la Antártica, el Campo de hielo Sur y Norte corresponden a la tercera reserva mundial de agua dulce. Sin embargo, reconocen una decepción inversamente proporcional: después de dos días de viaje, se encuentran sin disponibilidad de alojamiento y escasos servicios de alimentación.

${ }^{15}$ Se trata de una formalización aglutinante de registros, los que fueron realizados en entrevistas en Coyhaique, Aysén y Punta Arenas. Estos indican una perspectiva "perversa", en la medida que en los últimos años de educación secundaria, los adolescentes y sus familias, conforme a redes de apoyo y recursos, deben tomar la decisión que favorezca la ampliación de expectativas. 